\title{
0 apoio institucional como método de análise-intervenção na Atenção Básica no Distrito Federal, Brasil
}

Helena Eri Shimizu(a)

Shimizu HE, Martins T. Institutional support as a method of analysis-intervention in Primary Health Care of the Federal District, Brazil. Interface (Botucatu). 2014; 18 Supl 1:1077-87.

This paper discusses the experiences of the process of institutional support in three primary health units of the Federal District, Brazil. Several meetings were held with the management team, professionals and workers of the Family Health Strategy to exercise the self-analysis of work processes, in this perspective the connections potentiating creative changes. Some devices have been deployed to facilitate co-management in primary health care and promote the democratization of management practices and attention. We conclude that institutional support is powerful strategy to stimulate workers involved with the transformation of the ways to manage and take care of patients, as well as their job satisfaction.

Keywords: Primary Health Care. Institutional support. Humanization of assistance. Policies formulation.
O artigo aborda experiências do processo do apoio institucional em três unidades de Atenção Básica (AB) do Distrito Federal (DF), Brasil. Foram realizados diversos encontros com a equipe da gestão, com os profissionais e trabalhadores da Estratégia Saúde da Família para exercitarem a autoanálise dos seus processos de trabalho, na perspectiva de caminhar nas conexões potencializadoras das mudanças criativas. Alguns dispositivos foram implantados, que facilitam a cogestão nas unidades e que promovem a democratização das práticas de gestão e da atenção. Concluise que o apoio institucional se constitui estratégia potente para estimular a manter os trabalhadores implicados com a transformação dos modos de gerir e do cuidar dos usuários, bem como com a sua satisfação no trabalho.

Palavras-chave: Atenção primária à saúde. Apoio institucional. Humanização da assistência. Formulação de políticas.
Teresa Martins ${ }^{(b)}$

\author{
Teresa Martins ${ }^{(b)}$
}




\section{Introdução}

A Atenção Primária à Saúde (APS) é considerada como o modelo mais adequado para redução dos agravos, sobretudo das doenças crônicas degenerativas que vêm crescendo a cada dia no país. Desde a década de 1990, sobretudo com a implantação do SUS, abdicou-se do conceito tradicional de APS, que compreende apenas como uma forma de organização do primeiro nível de atenção e/ou uma forma de atender as demandas de saúde das populações pobres. A partir daí, passou-se a assumir a visão de APS, denominada de Atenção Básica (AB), como uma filosofia de organização, tanto estrutural quanto conceitual, de todo o sistema de saúde 1 .

Nessa perspectiva, $A B$ está comprometida com a mudança do modelo de atenção, que tem como um de seus pilares a reorganização do processo de trabalho de diversos profissionais de saúde e inovações no que tange ao relacionamento desses profissionais com a população. Nesse modelo são requeridas práticas gerenciais e sanitárias democráticas e participativas, sob a forma de trabalho em equipe, e dirigidas a populações de territórios bem delimitados, pelas quais assume a responsabilidade sanitária ${ }^{1}$.

A Estratégia Saúde da Família (ESF) é considerada fundamental para operacionalização desse novo modelo de atenção na perspectiva de reorganização do modelo assistencial e na difusão de novas práticas que visam oferecer ao usuário um melhor acesso aos serviços, um acompanhamento integral de suas demandas e uma melhor orientação à família e à comunidade local².

A Política Nacional de Humanização (PNH) tem feito investimentos teóricos e práticos para contribuir com a mudança no modelo de atenção, sobretudo para imprimir a humanização, na gestão e na atenção, considerando-as indissociáveis ${ }^{3,4}$. Os seus objetivos são promover mudanças no modelo burocrático e verticalizado que caracteriza, muitas vezes, os serviços e, consequentemente, as práticas de gestão e da atenção no campo da saúde.

Os esforços da PNH têm sido de definir novos modos de atuação na área da saúde para que rompam a fragmentação do processo de trabalho, por meio de dispositivos que permitam a construção da gestão participativa. Nessa lógica, entende-se que as mudanças nos modos de fazer a gestão e atenção em saúde envolvem diretamente a maneira como os sujeitos compõem coletivos de trabalho com suas experiências concretas emanadas das relações cotidianas. Ademais, parte-se do pressuposto de que as mudanças não se fazem sem um processo de produção de subjetividade que é sempre coletivo, histórico e determinado por múltiplos vetores. Esses vetores são inseparáveis na produção da saúde: sujeitos (desejos, necessidades, interesses), processos de trabalho (saberes), poder (modos de estabelecer as relações) e políticas públicas (coletivização dessas relações) ${ }^{5,6}$.

A formação de apoiadores institucionais tem sido uma das estratégias adotadas pela PNH para ampliar a democracia institucional nos serviços de saúde. Campos ${ }^{6}$ afirma que a função do apoiador institucional é ajudar na gestão e na organização de processos de trabalho, na construção de espaços coletivos nos quais os grupos analisam, definem tarefas e elaboram projetos de intervenção. É um processo que inclui a troca dos saberes, a circulação de afetos, especialmente a criação de processos de trabalho que não distanciem as atividades da gestão e da atenção.

Assim, o objetivo geral deste artigo é analisar as experiências de processo de desenvolvimento do apoio institucional em três unidades de $A B$, mais especificamente ESF do Distrito Federal, com a finalidade de destacar os movimentos instituídos e instituintes que ocorram no desenvolvimento do processo de trabalho.

\section{Método}

Trata-se de uma pesquisa participante, que utilizou como referencial o método de apoio institucional, que se expressa num modo de fazer que estimule a criação da grupalidade, na análise dos processos de trabalho e na problematização dos modos de gestão e do cuidar ${ }^{5,6}$.

Seguindo os referenciais $\mathrm{PNH}$, por grupalidade entende-se um coletivo que compõe uma rede em conexão, implicados com a produção de saúde e com a produção da subjetividade no desempenho 
do processo de trabalho. Para tanto, é preciso haver deslocamento subjetivo dos atores envolvidos - que passam à condição de autores dos processos de trabalho e não meros executores - portanto protagonista do trabalho $0^{5,7,8}$.

Outro conceito importante do referencial adotado neste estudo é o de operatividade, que se relaciona com a mudança das posturas e práticas. Operar, para Pichon-Rivière ${ }^{9}$, é promover uma modificação criativa da realidade. Diversos vetores fazem parte desse processo: afiliação, pertença, cooperação, aprendizagem e telê.

Foram escolhidas, conjuntamente, apoiadores da $\mathrm{PNH}$ e coordenadores da $\mathrm{AB}$, três unidades da ESF do Distrito Federal para serem apoiadas. Todas as unidades eram campos de estágio de alunos de cursos de graduação, critério considerado relevante para investir-se na implantação do processo de apoio institucional.

Para garantir o anonimato das unidades, foram nomeadas com nome de flores, e denominadas, a saber: experiência 1) Unidade Margarida; experiência 2) Unidade Rosa; experiência 3) Unidade Violeta. A "experiência" é diferente de "experimentação", porque a experiência é sempre em parte "encontro" 10,11, neste estudo, enfatiza-se o encontro do coletivo de trabalho para provocar mudanças no processo de trabalho na $A B$.

Foram realizados diversos encontros grupais com a equipe da gestão e com os profissionais e trabalhadores das unidades. Utilizaram-se diversas estratégias lúdicas, como o desenho, para estimular o espaço da fala. Fez-se uso de diários de campo para registrar as dinâmicas dos encontros.

O processo de apoio ocorreu, no período de janeiro de 2009 a maio de 2010, com diversos encontros com os seguintes atores da $A B$, gestores centrais, coordenadores regionais, profissionais $e$ trabalhadores da saúde.

O projeto de pesquisa foi aprovado pelo Comitê de Ética em Pesquisa da Faculdade de Ciências da Saúde. Todos os participantes da pesquisa assinaram o Termo de Consentimento Livre e Esclarecido.

\section{Resultados}

O primeiro momento consistiu na contratualização do projeto com os gestores da $A B$, do nível central (coordenador geral da $A B$ ), que ocorreu por meio da apresentação do projeto que enfatizava o compromisso de aprimorar o processo de trabalho. Houve aceitação imediata, o que deu possibilidade para, posteriormente, contatar os gestores do nível intermediário (coordenadores regionais da $A B$ ). No nível da gestão intermediário, no início, observou-se certa resistência para participar do projeto, entretanto, após alguns encontros, foi possível pactuar algumas ações, bem como reafirmar a indicação das unidades a serem apoiadas.

A contratualização é um momento muito importante, que visa pactuar a forma de trabalho. Construir um contrato que estabelece expectativas, objetivos, regras, métodos. Para tanto, alguns aspectos devem ser destacados: o sigilo das informações que circulam no grupo, que o espaço deve ser protegido, onde ocorra liberdade para criticas e questionamentos positivos, a duração das atividades, as avaliações processuais ${ }^{12}$, entre outros. O atropelamento dessas etapas pode prejudicar demasiadamente a operatividade do grupo.

O segundo momento consistiu na apresentação do projeto para as coordenações regionais e para os profissionais de saúde das unidades da ESF, que aceitaram com bastante entusiasmo participar do projeto que visava ampliar a gestão participativa no processo de trabalho na $A B$, sobretudo pela possibilidade dos encontros consistirem em espaço de fala das ansiedades vivenciadas nas unidades de saúde.

Inicialmente, foram explorados com as coordenações regionais e com os profissionais de saúde os sentimentos suscitados pelo trabalho. Diversos depoimentos registraram o grande desgaste vivenciado no cotidiano de trabalho, sobretudo a sobrecarga advinda da baixa cobertura da ESF no DF. Além disso, os trabalhadores expressaram a expectativa de que o projeto pudesse possibilitar um espaço para a "fala" das angústias sentidas em um trabalho que, muitas vezes, é sentido como solitário.

Em outros momentos, foram trabalhados os significados da ESF com as coordenações locais e com os profissionais de saúde, realizadas, por meio de estratégias lúdicas, especialmente os desenhos, os 
quais demonstraram a expressão de sentimentos muito positivos, como uma bonita casa, a qual acolhe as pessoas, um grupo de pessoas, o qual revela que o trabalho deve ser desenvolvido em equipe.

Posteriormente, passou-se para o momento de preparação dos apoiadores locais por meio da oferta da discussão sobre: o processo de trabalho em saúde; os dispositivos da $\mathrm{PNH}$; a ergologia para o aprimoramento da gestão e da atenção; e a função apoiadora.

A discussão da função apoiadora se deu por meio da oferta de texto ao grupo, com a definição do que é ser apoiador, o seu lugar, as suas responsabilidades, dentre outros aspectos. Além disso, foram realizados alguns encontros para aprofundar a discussão sobre o método. Observou-se grande estranhamento do método pelos profissionais, que resistiram em diversos momentos, especialmente ao colocar a impossibilidade de aplicar um método tão complexo na prática cotidiana das unidades.

Em realidade, grande parte das dificuldades em assimilar o novo método do apoio advém do modelo taylorista de processo de trabalho extremamente arraigado nos serviços e nas práticas dos profissionais. Nesse modelo gestão de processo de trabalho, os trabalhadores têm pouca reflexão sobre o uso de si, bem como de apropriar-se do que produzem, de sua obra. 6,10,11,13.

Foram realizados também seminários teóricos sobre ergologia, visando refletir sobre a maneira de entender o trabalho, bem como a responsabilidade dos gestores em propiciar renomatização dos processos de trabalho. Ademais, vislumbrou-se aprofundar como os referencias da PNH e da ergologia, considerados potentes para repensar os modos de fazer a gestão e cuidado na AB.

Além disso, foram realizadas ofertas teóricas em forma de grupos de discussão sobre modelos de gestão participativa, quando se observou que os apoiadores locais necessitavam problematizar com mais profundidade sobre as concepções que embasam a cogestão. Ocorreu também uma discussão sobre as diferentes formas de compreender o território, que carregam distintas concepções de processo saúde-doença ${ }^{14}$, portanto modulam as políticas de saúde.

Posteriormente, no terceiro momento, os profissionais comprometeram-se em preparar a apresentação da proposta de trabalho do apoio nas unidades. Assim, um grupo de profissionais da unidade, denominado de apoiadores locais, responsabilizou-se em apresentar a proposta de trabalho aos trabalhadores.

Destarte, dois apoiadores da PNH passaram a apoiar os apoiadores locais na construção do processo de cogestão nas unidades. Dessa feita, o terceiro momento ocorreu nas unidades, a saber:

\section{Experiência 1 - Unidade Margarida}

O bairro onde está inserida a Unidade Margarida está localizado em uma das mais críticas áreas do Distrito Federal. Em realidade, o bairro nasceu na década de 1960, após a inauguração de Brasília, com o surgimento de barracos de catadores de lixo do local, que deu origem, à época, ao "Lixão da Estrutural". As condições do bairro melhoraram, mas existem áreas mais carentes, sobretudo de infraestrutura urbana.

$\mathrm{Na}$ Unidade Margarida conviviam seis equipes da ESF, uma equipe do Nasf e uma equipe de Pronto Atendimento. Trata-se de uma unidade relativamente nova, aparentemente bem organizada, com ambiente agradável.

Houve um pouco de demora em agendar o encontro com os trabalhadores da unidade, o que só ocorreu após algumas insistências dos coordenadores da PNH. Usualmente participavam cerca de 25 trabalhadores (médicos, enfermeiros, nutricionista, auxiliares, ACS).

O primeiro encontro foi permeado de muitas expectativas e estranhamentos, possivelmente estimulado por questionamentos como: O que vieram fazer aqui? Será que podem nos ajudar? Ou isso nos dará mais trabalho?

Embora a equipe tivesse concordado com a necessidade de introduzir em sua rotina reuniões para discussão do processo de trabalho, esses encontros, no início, foram irregulares, atravessados por uma série de eventos tais como aulas de especialização dos apoiadores locais, envolvimento das equipes em escalas de atendimento para a gripe H1N1, campanhas de vacinação, além de uma agenda sempre lotada de consultas. 
Insistiu-se na importância da manutenção de uma agenda mínima de reunião da equipe conosco e entre as equipes da unidade. Para nós, apoiadores da PNH, o cumprimento dessa agenda era um produto importante do projeto, porque se trata de um desafio para eles redefinirem a finalidade da equipe e do serviço, planejarem coletivamente o processo de trabalho na unidade e, sobretudo, apropriar-se mais do território.

Foi interessante notar que a presença de gestores da equipe central da $A B$ permitiu negociar diversas questões de infraestrutura da unidade. Houve também diversos momentos de tensionamento com a gestão, pois as equipes da ESF sentiram-se "desrespeitadas" quando houve a implantação da Unidade de Pronto Atendimento (PA), sem consulta previa aos trabalhadores da Unidade. A abertura do PA implicava em atender nas 24 horas, e também as equipes não se sentiam competentes tecnicamente para atender os usuários mais graves.

Os gestores da AB explicaram que o PA era um projeto de Governo, ou seja, a Secretaria de Saúde havia assumido, juntamente com o governo do Distrito Federal, a criação de algumas dessas unidades para resolução rápida dos problemas mais graves de saúde. Apesar da insatisfação gerada, por não terem sido consultados sobre a instalação do PA, passou-se a discutir formas para reorganizar as equipes e os processos de trabalho para o PA e para as unidades de ESF.

Nos encontros iniciais, que contava com a presença dos gestores da $A B$, do nível central, e profissionais, de nível superior, havia discussão sobre a necessidade de o trabalho ser mais significativo para os trabalhadores, sobretudo questionavam a necessidade de sair da "rotina" para realizarem um trabalho mais criativo.

O envolvimento dos gestores nas rodas de discussão é fundamental, pois aumentam as oportunidades para resolução de problemas mais complexos, além de diminuir a sensação de solidão das equipes.

Ao analisar os indicadores da unidade, observou-se que grande parte do trabalho era realizada nas unidades, ou seja, as visitas domiciliares e outras atividades extramuros eram escassas. Além disso, constatou-se que a maioria das ações desenvolvidas nas unidades seguia o modelo biomédico, centrada, sobretudo nas consultas médicas e de enfermagem, algumas feitas pelos profissionais do Nasf.

Essas questões foram trazidas em alguns encontros para as rodas. Num primeiro momento não geraram reações positivas, mas, com o passar do tempo, foram discutidas a valorização das ações que envolviam a comunidade, como a escola, os conselhos locais e algumas atividades que envolviam outros setores (atividade física com os idosos).

Com o passar do tempo, os trabalhadores de nível técnico e os ACSs também foram incluídos na roda ao se discutir a situação dos moradores que residiam nas microáreas de cada uma das equipes. Observava-se um vínculo das equipes com as famílias que viviam em condições bastante precárias.

Outra forma encontrada pela equipe para aproximar-se da comunidade foi a busca de um grupo de quase noventa mulheres, moradoras da Estrutural, chamado de "Mulheres da Paz".

Finalmente, as equipes decidiram criar o colegiado gestor de unidades. E, para tanto, foram realizadas diversas reuniões para discutirem a importância do colegiado gestor, bem como de quem comporia o colegiado gestor. Depois dessa definição, passou-se a eleição do colegiado gestor da unidade. Após algum tempo de seu funcionamento, a avaliação era de resolução mais rápida dos problemas devido à descentralização das decisões, menor sobrecarga da chefia e maior responsabilização de todos os setores envolvidos nesse colegiado.

\section{Experiência 2 - Unidade Rosa}

A Unidade Rosa está localizada na cidade do Itapoã, que é fruto de "ocupação" relativamente recente (dez anos). É uma região bastante pobre e violenta. Com pouca infraestrutura de serviços públicos. O asfaltamento das ruas principais chegara há pouco tempo, antes era muita poeira vermelha. Possui atualmente cerca de cento e oitenta mil habitantes, entretanto o GDF reconhece cerca de setenta mil a oitenta mil. Logo, a projeção de serviços de saúde cobre apenas esse quantitativo. 
A unidade comporta duas equipes da ESF, que foram os primeiros serviços básicos de saúde da região. Ressalta-se que, por muito tempo, a unidade conviveu com equipes incompletas, mormente com a falta de médicos. As enfermeiras eram a principal referência para a comunidade. Houve relato de que nenhum profissional queria trabalhar nessa unidade, pois era estigmatizada, sobretudo devido à violência na região.

Nos encontros com a equipe, que contava com a média de 15 trabalhadores, médicos, enfermeiros, auxiliares de enfermagem, Agente Comunitário de Saúde, segurança, copeira, observava-se que todos estavam bastante implicados com o trabalho, mas bastante sobrecarregados, porque a população atendida ultrapassava sobremaneira o preconizado para cada equipe da ESF. Já que se tratava de um bairro novo em pleno crescimento desornando, que a cada dia recebe novos moradores. Observavase que os trabalhadores se sentiam na obrigação de assumir todos os moradores que chegavam e que viviam em precárias condições, portanto, com carência de todas as ordens.

Em meio a tantos sofrimentos, dos trabalhadores e dos usuários, observava-se também vivência de grande prazer, especialmente ao reviverem essas sensações no coletivo; eram situações de usuários que apresentaram sucesso, usualmente como resultado de grande esforço da equipe, quase heroico.

Nesse processo, realizou-se a avaliação do processo de trabalho que foi considerada positiva, apesar da constatação das precárias condições de trabalho (ausência de telefone, falta de aparelhos para medir pressão arterial, medicamentos, insumos para realização de procedimentos). A equipe demonstrou que buscava superar essas dificuldades para atender as necessidades da comunidade, quase sempre com esforços pessoais intensos, o que gerava aumento dos sentimentos de desgaste e de sensação de falta de atenção do nível central.

O "ativismo" da equipe estava causando problemas de relacionamento interpessoal, que tem sido trabalhado de diversas formas pela equipe: reuniões dentro e fora da unidade, criação de espaços para falar sobre como o outro tem desenvolvido o trabalho e o reflexo disso na relação com usuário.

Diante dessa constatação, as equipes decidiram trabalhar o projeto "Cuidando do cuidador". As equipes passaram a se reunir com certa regularidade para discutir as questões de cada equipe e entre as duas equipes.

O espaço da fala no coletivo permitia também que a equipe percebesse os motivos geradores de desgaste, ao mesmo tempo, a todo o momento, que se reavivasse a expressão dos sentimentos de prazer e sofrimento no trabalho. A vivência desses sentimentos parecia estimular maior reflexão sobre o processo de trabalho, sobre os possíveis novos modos de fazer mais humanizado, o que pode ser nominado de processo renormatização, bastante importante para o processo criativo. Nesse sentido, Merhy ${ }^{15}$ destaca que o processo de trabalho deve incluir os meios para que se realize o trabalho vivo em ato.

Após esses ricos momentos, houve dificuldade para retornar à unidade, talvez porque havia situações que o grupo tinha que elaborar sem a presença dos apoiadores da $\mathrm{PNH}$. O apoio é um lugar-função que instiga, que viabiliza processos de desestabilização do que estão instituídos, fazendo emergir afetos, por vezes, difíceis de serem suportados $5,6,8,16,17$.

Ao retornar para a unidade, alguns conflitos emergiram, relacionados ao não cumprimento de horário de alguns trabalhadores que sobrecarregavam mais ainda os outros. Foi interessante observar que eles tomaram coragem para colocar os conflitos na roda, na presença da chefia da unidade, que se viu obrigada a falar também sobre os problemas que enfrenta para gerir a unidade.

O grupo sentiu-se mais fortalecido para criar outros projetos internos, para eles mesmos, que se denominava "Cuidando do cuidador" e outros para fora, que envolviam a comunidade. Existem pelo menos dois grupos com a participação da comunidade: idosos e das mulheres vítimas de agressões.

Como resultado desse processo houve melhora na grupalidade, eles conseguiram trazer a gestão regional para discutir os problemas da unidade. Além disso, uma das equipes, por meio da ficha $\mathrm{A}$ e das visitas às casas, fez um mapeamento real da população que vive na área de abrangência para negociar com a gestão a delimitação da população da responsabilidade da equipe.

Os encontros permitiram também maior diálogo entre as duas equipes, que decidiram realizar um planejamento conjunto, tendo como ponto de partido o recadastramento das famílias. Mas, desta vez, pactuaram com a gestão Regional da $A B$, que as equipes atenderiam apenas a população 
adscrita. Finalmente a equipe se sentiu mais fortalecida para reconhecer seus limites para atender às necessidades demandadas pelos usuários e fez movimentos para preservar alguma qualidade naquilo que podem produzir como ações de saúde.

\section{Experiência 3 - Unidade Violeta}

Tratava-se de uma unidade nova, localizada no mesmo bairro da Unidade Rosa. O Centro de Saúde foi caracterizado com perfil de unidade mista: cinco Equipes de Saúde da Família - ESF (sem Agente Comunitário), profissionais do Nasf (terapeuta ocupacional, serviço social, ginecologista e pediatra) e profissionais para realização do pronto-atendimento. A equipe de saúde bucal atuava de forma isolada e era composta por uma cirurgiã-dentista e uma atendente de consultório dentário. $\mathrm{O}$ agendamento de novos atendimentos não estava sendo feito, pois havia uma lista de espera com mais de quatrocentas pessoas inscritas.

Havia um temor generalizado de que a unidade se tornasse uma unidade de pronto-atendimento e referência regional na atenção às emergências em saúde, uma vez que as ESFs não estavam definidas, não tinham definição de área adscrita e os profissionais médicos eram deslocados frequentemente para atender demandas em outras unidades na regional.

Os apoiadores locais fizeram a apresentação do projeto e dos apoiadores da PNH. Vale ressaltar que havia grande expectativa dos apoiadores locais para que o projeto ajudasse a Unidade a funcionar da melhor forma possível. Os grupos de encontros eram muito grandes, com a participação de cerca de trinta a 35 pessoas.

Iniciou-se o processo de apoio-pesquisa a partir da realização de uma roda de conversa sobre a intencionalidade das ações realizadas no Centro de Saúde. Os participantes identificaram a necessidade de pensar a finalidade do trabalho em saúde realizado na unidade, a partir do levantamento das necessidades da comunidade e dos profissionais, à luz das diretrizes nacionais para a $A B$ (PNAB).

Dois encontros foram destinados para aprofundar a compreensão sobre o que é $A B$ e as atribuições da Estratégia de Saúde da Família. As necessidades de natureza estrutural mereceram destaque como as barreiras ao cumprimento das atribuições de uma unidade da ESF (sem telefone, internet, computadores, sem pessoal administrativo, ACSs).

Nos primeiros encontros, refletiu-se sobre a dificuldade das equipes de implantar novas práticas, sobretudo devido ao modelo de formação recebido, as experiências prévias de boa parte dos profissionais eram em hospitais ou centros de saúde tradicional.

Apesar de momentos centrados nas queixas, observou-se que o grupo refletia coletivamente sobre os possíveis novos modos de fazer na unidade. Aos poucos os trabalhadores, sobretudos os ACSs trouxeram para o grupo a demanda dos moradores, que ia além do que o serviço ofertava. As precariedades das condições sociais e econômicas eram refletidas nas situações de violência, abandono e, algumas vezes, de miséria da comunidade. Essa discussão trazia para dentro do grupo a necessidade de pensar novas formas de cuidar da comunidade, que envolvia todos os trabalhadores da unidade. Aos poucos, a maioria dos trabalhadores ficou sensibilizada com os casos trazidos pelo ACSs passando a discutir outras possibilidades de cuidar da comunidade.

Foi feito, então, pelos apoiadores da $\mathrm{PNH}$, a oferta da discussão sobre projetos terapêuticos singulares, compreendido como coprodução de processo terapêutico de pessoas ou coletivos em situações de vulnerabilidade ${ }^{18}$, que interessou a vários trabalhadores os quais passaram a opinar como poderiam colocar esses projetos em prática. Combinou-se que alguns casos seriam trazidos para se discutir as possiblidades para a criação do projeto terapêutico. Foram discutidos três projetos terapêuticos, nos quais se observou que os diversos profissionais, que antes não se envolviam com o trabalho feito pelo outro, ofereciam-se para complementar o cuidado.

A satisfação dos ACSs em contar com o apoio de outros profissionais da equipe para elaboração e execução do projeto terapêutico era visível, pois se sentiam saindo da grande solidão para efetivamente trabalhar em equipe. As equipes definiram uma reunião semanal para a discussão dos casos mais graves atendidos pelas equipes, sobretudo para planejar as ações que envolvem outros profissionais, outros serviços ou setores. 
Já no terceiro encontro foi proposta a formação de um grupo gestor, visando implementar a gestão colegiada mediante a participação de representantes de todas as categorias profissionais. Este "conselho gestor" está formalizando seu regimento e realiza suas reuniões semanalmente, às quintas-feiras.

Foi criado também na unidade, o colegiado gestor de unidade, que envolve a representação dos diversos serviços e das diversas categorias profissionais, que se reúnem quinzenalmente para discutirem o processo de gestão da Unidade.

\section{Análise do processo de intervenção}

As experiências acima relatadas demonstraram que a estratégia de apoio institucional, tomada como método de intervenção, permitiu aos coletivos de trabalho da $A B$ enxergarem com mais clareza os processos de trabalho instituídos, que, mormente estavam muito cristalizados, e anestesiavam a criatividade e inventividade dos trabalhadores.

Entretanto, há de se destacar que o processo de apoio institucional não foi facilmente aceito pelos coletivos da $A B$, houve resistências que foram expressas de diversas formas, sendo a mais usual, a não aceitação imediata dos apoiadores da PNH. Esforços de aproximação constante foram negociados até o momento da aceitação da entrada na dinâmica dos serviços.

Em realidade, parte da rejeição inicial dos apoiadores da PNH pode ser explicada não só pelo estranhamento da presença de membros externos aos serviços, mas também pela proposta da gestão compartilhada, que pode ter lhes parecido sinistra, porque rompe com o modelo gestão taylorista. Modelo que abarca grande número de prescrições, que contribui para manter os trabalhadores mais passivos, mas que pode lhes conferir a sensação de comodidade.

Pichon-Rivière ${ }^{9}$ explica que toda situação de mudança gera ansiedade, devido aos medos básicos de ataque e perda implícitos nas relações, os quais podem prejudicar a comunicação grupal quando não explicitados. Quando esse tipo de sentimento era elaborado, os coletivos abriam-se mais para a experiência de serem apoiados, ou seja, conseguiam ultrapassar a fase da pré-tarefa, que caracteriza-se pela resistência para enfrentar a nova tarefa.

Aos apoiadores institucionais, coube se comprometer com as equipes e comunicar suas avaliações e suas análises. Nesse sentido, requereu empenho no sentido envolver a discussão/problematização dos modos como a gestão nas relações de trabalho se expressavam.

Observou-se que os coletivos da $A B$ passaram por diversos vetores que percorrem o processo grupal ${ }^{9}$, a saber: a afiliação - um grau de identificação dos integrantes entre si e com a tarefa. Notadamente isso ocorria quando os coletivos conseguiam rever mais criticamente os processos de trabalho realizados e perceber que poderiam fazer diferente. A criatividade coletiva começava ascender para a inventividade no trabalho.

O olhar analítico sobre as suas próprias práticas permitiu, aos trabalhadores, criar e recriar seus modos de fazer e de enfrentar o que se apresentava como real no desempenho de suas atividades ${ }^{19}$. Tratou-se da criação de processos instituintes, que permitiram a superação da rotinização do trabalho que gerava mais desgaste nos trabalhadores.

Outro momento percorrido pelo grupo foi o processo pertença - quando há um maior grau de identificação e integração no grupo, permitindo a elaboração da tarefa ${ }^{9}$. Isso ocorria quando os coletivos conseguiam elaborar propostas mais concretas de mudanças nos processos de trabalho, o que eles chamaram de projetos, que ocorreu depois de um tempo relativamente longo.

O tempo da produção coletiva e reflexiva é de outra ordem; demorado. Parece que ainda não foi possível decifrar o enigma da esfinge para que se conseguir criar estratégias a fim de gerir e gerar o cuidado. Com isso, questiona-se os tempos que não se coincidem: aqueles da produção coletiva e dos tempos cronológicos e produtivistas da gestão.

É importante destacar que todas as unidades, de alguma forma, organizaram-se para ter um lugar e um tempo para processar e analisar o que fazem cotidianamente, especialmente a criação dos colegiados gestores. Esse tipo de prática é fundamental, criar e instituir espaços nos quais se possa 
experimentar tomada de decisões coletivas que permitam a formulação de projetos. O ideal é que esses espaços se tornem instâncias, que permitam processar continuamente as demandas do coletivo, com o propósito de ter um grau de análise da implicação maior com aquilo que produzem ${ }^{13}$.

Esses espaços permitem a criação do que Pichon-Rivière ${ }^{9}$ denomina de cooperação - o qual pressupõe o desempenho de papéis diferenciados e complementares, de tal modo, que cada um contribui com o que sabe e com o que pode; em um movimento grupal manifestada pela capacidade de se colocar no lugar do outro.

Observou-se que houve melhora da comunicação entre membros da equipe e interequipes, considerado por Pichon-Rivière ${ }^{9}$, o mais importante de todos os vetores, que pressupõe um intercâmbio de significados, a mensagem vai circular por um canal que inclui ruídos e deverá ser decodificada pelo receptor, podendo ser verbal ou não verbal ${ }^{20}$. Esse vetor é considerado por Pichon ${ }^{9}$ como o lugar central pelo qual se expressam os transtornos e dificuldades do grupo para enfrentar a tarefa.

Na medida em que cada transtorno da comunicação se remete a um transtorno da aprendizagem, é possível verificar os sujeitos grupais tratando de desenvolver velhas atitudes, em geral mal aprendidas, com a intenção de abordar os objetos novos de conhecimento. Na visão do autor em pauta, toda alteração da comunicação grupal se deve a uma dificuldade na aprendizagem e vice-versa9 .

A aprendizagem é outro vetor relevante, estreitamente ligado à comunicação e às suas alterações; é um processo que envolve criação, adaptação ativa à realidade, as fragmentações e as integrações dos saltos de qualidade que incluem a tese-antítese-síntese. É entendido como a ruptura de certos estereótipos de comunicação e a obtenção de novos estilos, o que implica sempre reestruturações e redistribuição dos papéis desempenhados pelos integrantes do grupo.

Por fim, em alguns momentos observou-se a presença do que Pichon-Rivière ${ }^{9}$, chama de telê-vetor que se refere ao clima afetivo que prepondera no grupo; é a disposição positiva ou negativa para trabalhar a tarefa grupal, é a aceitação ou a rejeição que os integrantes têm espontaneamente em relação aos demais. Os vetores guardam entre si uma inter-relação, sendo que a análise da comunicação pode ser indicativa de como estão os demais vetores.

\section{Tecendo algumas considerações finais}

Conclui-se que o apoio institucional se constitui estratégia potente para estimular e manter os trabalhadores implicados com a transformação dos modos de gerir e do cuidar dos usuários na ESF, bem como com a sua satisfação no trabalho.

Por fim, destaca-se que não se trata de um método de fácil operacionalização, pois exige investimento, especialmente na educação permanente para formação de apoiadores institucionais, e só se sustenta se houver investimento continuado para sua implementação.

Trata-se de uma nova forma de gerar e de gerir, numa relação dinâmica que se estabelece entre o apoiador institucional e a equipe apoiada que objetiva dinamizar a produção de coletivos organizados e ajudar a articular a produção de serviços, de instituições e dos próprios sujeitos, visando à cogestão.

\section{Colaboradores}

Os autores trabalharam igualmente na construção do artigo, em suas etapas de formulação, redação e revisão. 


\section{Agradecimentos}

A Daís Gonçalves Rocha, que colaborou no apoio das unidades Violeta e Rosa, e Alessandra Pereira da Silva, que colaborou no apoio da Unidade Margarida.

\section{Referências}

1. Ministério da Saúde. Política Nacional de Atenção Básica. Brasília (DF): Ministério da Saúde; 2012. (Série E, Legislação em Saúde)

2. Escorel S, Giovanella L, Mendonça MHM, Senna MCMO. O Programa de Saúde da Família e a construção de um novo modelo para a atenção básica no Brasil. Rev Panam Salud Publica. 2007; 21(2):164-76.

3. Benevides R, Passos E. Humanização na saúde: um novo modismo? Interface (Botucatu). 2005; 9(17):389-406.

4. Benevides R, Passos E. A humanização como dimensão pública das políticas de saúde. Cienc Saude Colet. 2005; 10(3):561-71.

5. Barros ME, Guedes CR, Roza MM. O apoio institucional como método de análiseintervenção no âmbito das políticas públicas de saúde: a experiência em um hospital geral. Cienc Saude Colet. 2011; 16(12):4803-14.

6. Campos GWS. Saúde Paidéia. São Paulo: Hucitec, Abrasco; 2003.

7. Santos-Filho SB, Barros MEB, organizadores. Trabalhador da saúde. Muito prazer! Protagonismo dos trabalhadores na gestão do trabalho em saúde. Ijuí: Unijuí; 2009. p. 11.

8. Campos GWS. O anti-Taylor: sobre a invenção de um método para co-governar instituições de saúde produzindo liberdade e compromisso. Cad Saude Publica. 1998; 14(4):863-70.

9. Pichon-Rivière E. O processo grupal. São Paulo: Martins Fontes; 1994.

10. Schwartz Y, Durrive L, organizadores. Travail \& ergologie: entretiens sur l'activité humaine. Toulouse France: Octarès; 2003.

11. Schwartz Y. A experiência é formadora? Educ Real. 2010; 35(1):35-48.

12. Cunha GT, Dantas DV. Uma contribuição para a co-gestão da clínica: grupos Balint-Paideia. In: Campos GWS, Guerrero VPA, organizadores. Manual de práticas de Atenção Básica: saúde ampliada e compartilhada. São Paulo: Hucitec, Abrasco; 2008. p. 34-60.

13. Onocko R. A gestão: espaço de intervenção, análise e especificidades técnicas. In: Campos GWS, organizador. Saúde Paideia. São Paulo: Hucitec, Abrasco; 2003. p.122-49.

14. Oliveira GN, Furlan PG. Co-produção de projetos coletivos e diferentes "olhares" sobre o território. In: Campos GW, Guerrero AVP, organizadores. Manual de práticas de atenção básica: saúde ampliada e compartilhada. São Paulo: Hucitec, Abrasco; 2008. p. 247-72.

15. Merhy EE. Em busca do tempo perdido: a micropolítica do trabalho vivo em saúde. In: Merhy EE, Onocko R, organizadores. Agir em saúde: um desafio para o público. São Paulo: Hucitec, Abrasco; 1997. p. 71-112.

16. Campos GWS. Prefácio. In: Santos-Filho SB, Barros MEB, organizadores. Trabalhador da saúde: muito prazer - protagonismo do trabalhador na gestão do trabalho em saúde. ljuí: Unijuí; 2007. p. 11.

17. Campos GWS. Subjetividade e administração de pessoal: Considerações sobre modos de gerenciar o trabalho em equipes e saúde. In: Merhy EE, Onocko R, organizadores. Agir em saúde: um desafio para o público. São Paulo: Hucitec, Abrasco; 1997. p. 229-66. 
18. Oliveira GN. O projeto terapêutico singular. In: Campos GW, Guerrero AVP, organizadores. Manual de práticas de atenção básica: saúde ampliada e compartilhada. São Paulo: Hucitec, Abrasco; 2008. p. 283-97.

19. Clot Y. A função psicológica do trabalho. Petrópolis: Vozes; 2006.

20. Rigobello LMM, Fortuna CM, Rigobello LL, Pereira MJB, Diniz SA. Processo de comunicação em grupos de aprendizagem: uma experiência multiprofissional. Rev Latino-am Enferm. 1998; 6(4):95-102.

Shimizu HE, Martins T. Apoyo institucional como método de análisis-intervención en la Atención Primaria del Distrito Federal, Brasil. Interface (Botucatu). 2014; 18 Supl 1:1077-87.

El artículo describe las experiencias del proceso de apoyo institucional en tres unidades de atención primaria del Distrito Federal, Brasil. Se realizaron varias reuniones con el equipo directivo, con los profesionales y trabajadores de la Estrategia Salud de la Familia para poner en práctica el auto-análisis de procesos de trabajo, desde esta perspectiva avanzar hacia las conexiones potencializadores de los cambios creativos. Algunos dispositivos se han desplegado para facilitar la co-gestión en la atención primaria de salud y la promoción de la democratización de las prácticas de gestión y atención. Llegamos a la conclusión de que el apoyo institucional constituye estrategia potente para estimular y mantener a los trabajadores involucrados en la transformación de las formas de administrar y cuidar de los usuarios, así como su satisfacción en el trabajo.

Palabras clave: Atención Primaria de Salud. Apoyo institucional. Humanización de la atención. Formulación de políticas. 
